\title{
Article \\ On the Set of Fellini's Movies: Investigating and Preserving Multi-Material Stage Costumes Exploiting Spectroscopic and Mass Spectrometric Techniques
}

\author{
Francesca Sabatini ${ }^{1}$, Jacopo La Nasa ${ }^{1}(1)$, Camilla Guerrini ${ }^{1}$, Francesca Modugno ${ }^{1, *}$, Sara Bonadio ${ }^{2}$, \\ Federica Ursino ${ }^{2}$, Isetta Tosini ${ }^{2}$, Maria Perla Colombini ${ }^{1}{ }^{10}$ and Ilaria Degano ${ }^{1, *}$ \\ 1 Department of Chemistry and Industrial Chemistry, University of Pisa, Via Moruzzi, 13, I-56126 Pisa, Italy; \\ f.sabatini4@gmail.com (F.S.); jacopo.lanasa@for.unipi.it (J.L.N.); kamill.96@hotmail.it (C.G.); \\ maria.perla.colombini@unipi.it (M.P.C.) \\ 2 Opificio Delle Pietre Dure (OPD), Via Alfani, 78, I-50121 Firenze, Italy; sara.bonadio@virgilio.it (S.B.); \\ derikkia@hotmail.it (F.U.); isetta.tosini@beniculturali.it (I.T.) \\ * Correspondence: francesca.modugno@unipi.it (F.M.); ilaria.degano@unipi.it (I.D.)
}

\section{check for}

updates

Citation: Sabatini, F.; La Nasa, J.; Guerrini, C.; Modugno, F.; Bonadio S.; Ursino, F.; Tosini, I.; Colombini, M.P.; Degano, I. On the Set of Fellini's Movies: Investigating and Preserving Multi-Material Stage Costumes Exploiting Spectroscopic and Mass Spectrometric Techniques. Appl. Sci. 2021, 11, 2954. https://doi.org/ 10.3390/app11072954

Academic Editor: Emanuela Bosco

Received: 1 March 2021

Accepted: 22 March 2021

Published: 25 March 2021

Publisher's Note: MDPI stays neutral with regard to jurisdictional claims in published maps and institutional affiliations.

Copyright: (c) 2021 by the authors. Licensee MDPI, Basel, Switzerland. This article is an open access article distributed under the terms and conditions of the Creative Commons Attribution (CC BY) license (https:// creativecommons.org/licenses/by/ $4.0 /)$.

\begin{abstract}
Since the second half of the 19th century, the world of textile production was radically changed both in terms of esthetics and of the performances leading to industrial products whose chemical properties were totally unknown and unexplored. Stage costumes are typical examples of multi-material art objects where different natural and synthetic materials were used to fulfil specific purposes. This research was performed in the framework of a diagnostic and restoration campaign of dresses of two Federico Fellini's movies ("Il Casanova" and "Roma"). For the characterization of the textile fibers, Attenuated Total Reflection Fourier Transform Infrared Spectroscopy (ATR-FTIR) and Pyrolysis Gas Chromatography coupled with Mass Spectrometry (Py-GC/MS) were employed. The structure of the metallic threads was investigated by Scanning Electron Microscopy coupled with Energy-Dispersive X-ray Spectroscopy (SEM-EDX). Dye identification was carried out by High Performance Liquid Chromatography coupled with Diode Array Detector and mass spectrometry (HPLC-DAD, HPLC-ESI-Q-ToF). The analytical approach adopted allowed us to fully characterize the costumes composed of natural, synthetic and artificial fibers dyed with complex mixtures of last generation synthetic dyes. The results collected were fundamental to fine-tune an effective restoration aimed at minimizing the damages due to ageing, inaccurate home-made restoration interventions, or poor conservation conditions.
\end{abstract}

Keywords: synthetic and artificial fibers; Py-GC/MS; HPLC-ESI-Q-ToF; stage costumes; Federico Fellini

\section{Introduction}

Textiles constitute a wide and miscellaneous group of materials that have been widely used since ancient times for making clothes and for domestic uses. The first evidences of weaving were provided by Andean civilizations, who intertwined and knotted plant fibers to form baskets and other containers [1]. Other relevant textile findings are composed of Egyptians linen textiles for mummification practices and Chinese silk fabric production [2]. The industrial revolution enabled the rapid production of textile fibers with tailored high-performant properties, and with low production costs. In the late 19th century, the introduction on the market of "Chardonnet silk," the first type of rayon commercialized, drastically increased the popularity of synthetic fibers undermining the long-lasting monopoly of natural ones [3]. Textile fibers can be classified as natural and man-made. The first category can be subdivided in vegetal (e.g., cotton, linen, hemp), animal (e.g., silk, wool, mohair, cashmere), and mineral (asbestos fiber). The latter category constitutes artificial fibers (e.g., rayon, viscose, Bemberg, modal, acetate, lyocell), produced by dissolving and regenerating natural polymers, and by synthetic ones (polyamide, 
polyester, acrylic, polyurethane, etc.), obtained by polymerization reactions of synthetic monomers [2]. At the present time, the production of colorful fabrics is achieved employing a wide variety of artificial dyes, selecting the most suitable dyeing methodologies (such as exhaust dyeing, continuous dyeing, and printing dyeing [4]) for the kind of textile fiber.

For a long time now, the techniques most frequently used for the analysis of natural and man-made fibers are based on microscopy observation. The appearance of a fiber under a microscope may provide information about the size, shape, surface topography, pigmentation, imperfections, morphology of the sample, on its state of conservation, and on the distribution of the possible dye applied. Fiber cross-section can also be observed. Ultraviolet light can also be used for illumination. Optical microscopy (OM) and, more often, polarized optical microscopy of single threads allow the investigation of structural details. Investigating samples in polarized light allows to observe birefringence of fibers, providing information on their crystalline regions. The obtained data can be used for fiber identification by comparing the values of the refractive index, parallel and perpendicular to the fiber axis, and birefringence of the unknown fiber to published tables.

Even if optical microscopy can provide important information, caution shall be applied when investigating man-made fibers, since they are often produced in a number of modifications which alter their longitudinal or cross-section appearance. Scanning Electron Microscopy (SEM) is also applied to evaluate the morphology of the single fibers, thanks to its higher magnification, and to examine surface coatings and assess degradation [5-7]. SEM equipped with Energy Dispersive X-ray Spectrometry also allows for elemental analysis to be performed, thus providing valuable information on the presence of inorganic contaminants on the fibers, and on the nature of metal threads [6].

To better assess the nature of an unknown thread, especially when dealing with synthetic fibers, Fourier Transform Infrared Spectroscopy, mainly in transmission [8-12], and Attenuated Total Reflection mode (ATR-FTIR) [13-16] are applied, due to their higher specificity, non-destructivity, and rapidity. Calorimetric techniques were also widely employed for polymer characterization, and the identification often integrated with FTIR measurements $[8,10]$. More recently, Pyrolysis Gas Chromatography coupled with Mass Spectrometry (Py-GC/MS) [14,17-19] and Evolved Gas Analysis coupled with Mass Spectrometry (EGA/MS) [15,20-22] have proven fundamental in the chemical analysis of polymers allowing their identification thanks to specific marker compounds. Finally, Scanning Electron Microscopy (SEM) [23-30] and X-ray Diffraction (XRD) [23,26,27,29,31] have been widely used to study the morphology and crystallinity of the fibers and to monitor the morphologic modifications undergone by the fibers structure and surface due to ageing or industrial processes.

At present, textile polymers are very popular and exploited in a great number of applications, including the field of the restoration of artworks. The characterization of not only the fabric but also the dye formulations used is widely important to disclose the complete composition of the artwork and select the most suitable materials for the restoration and conservation practices. Several studies are reported in the literature on the identification of synthetic organic dyes and pigments in paintings, or in paint and textile mockups, while only few are dedicated to synthetic organic dyes detection in 19th historical textile archives and modern costumes. In these cases, synthetic dye recognition was performed by 3D Fluorescence [32], Raman and Surface Enhanced Raman Spectroscopy (SERS) [33] and High Performance Liquid Chromatography coupled with Diode Array Detector and Mass Spectrometer detector (HPLC-DAD-MS) [34-38].

This study focuses on two stage costumes used in Federico Fellini movies: the exquisite dress of the "golden lady" in "Il Casanova" (1976) and the tunic and the chasuble worn by a bishop in "Roma" (1927). Federico Fellini (Rimini, 1920-Rome, 1993) could be considered one of the greatest, most influential, and most creative directors and screenwriters of all time. Several of his movies were awarded with national and international prizes, including ones for Best Costumes. The creative and prolific Danilo Donati (Suzzara, 1926-Rome, 2001) was one of the costume designers with whom Fellini used to collaborate. Donati was 
awarded with the Best Costume prize for the innovative and eccentric creations prepared for "Il Casanova di Federico Fellini." After the shooting of the movie, the costumes analyzed in this work were bought by Giuseppe Bruno Bossio, who owns a deposit of stage costumes in Rome, and later by the Cineteca Comunale di Rimini-Archivio Federico Fellini [39]. To celebrate the centennial of Fellini's birth, a museum dedicated to the Italian director will be opened in Rimini, and the stage costumes will be on display for the exhibition. Thus, the Opificio delle Pietre Dure (OPD, Florence) was charged with the restoration campaign of these innovative artworks. The costumes are characterized by the copresence of miscellaneous executive techniques and fabrics with different chemical and physical features. These peculiarities make their restoration extremely complex. Thus, a preliminary study of the historical background and of the technical properties of the fabrics present is fundamental for their characterization and describing the executive techniques and the relative degradation phenomena. Even if the stage costumes are relatively recent, they were stored in unsuitable conditions, re-used for carnival parties, and modified to address these purposes. The re-use and the customization of the stage costumes strongly affected their integrity, since they were originally designed to last for just one movie [40].

In order to provide information fundamental for the interventions, to shed light on the nature of the fabrics and the dyes employed in such multi-material objects, representative samples were taken from the costumes and analyzed with a combined analytical approach based on OM, ATR-FTIR, SEM-EDX, Py-GC/MS, HPLC-DAD, and Liquid Chromatography coupled with high-resolution mass spectrometry (HPLC-ESI-Q-ToF). The relative performances of the different techniques were evaluated in providing complementary information.

The characterization and preservation of contemporary artworks, such as stage costumes, are of paramount important for keeping track of the evolution of textile and dyeing technologies, and this study is a promising starting point for the simultaneous study of both the fibers and the dyes in modern textiles.

\section{Materials and Methods}

2.1. Samples

\subsubsection{Reference Materials}

The reference Bemberg analyzed belongs to the database of OPD restoration materials.

\subsubsection{Historical Samples}

Fifteen samples were analyzed: 13 were collected from different parts of the dress of the "golden lady" in "Il Casanova" (sample C1-C5, C7-C14) and the other two from a bishop tunic (sample T) and chasuble (sample P) featuring in "Roma." The sample locations are highlighted in Figure 1.

Due to the tiny size and limited amount of sample available, it was not possible to apply all four analytical techniques to each of them. For the identification of the kind of fiber, all the samples which fit the ATR-FTIR set-up were preliminary analyzed and, whenever possible, Py-GC/MS was applied for confirmation. SEM-EDX was used for revealing the morphology and the stratigraphy of the metallic threads. HPLC-DAD and HPLC-ESI-Q-ToF were only applied to the yellow and bluish-blackish colored samples for detecting the organic dyes possibly present. The sample list with the relative sampling location and the analyses performed are reported in Table S1 (Supplementary Materials). 

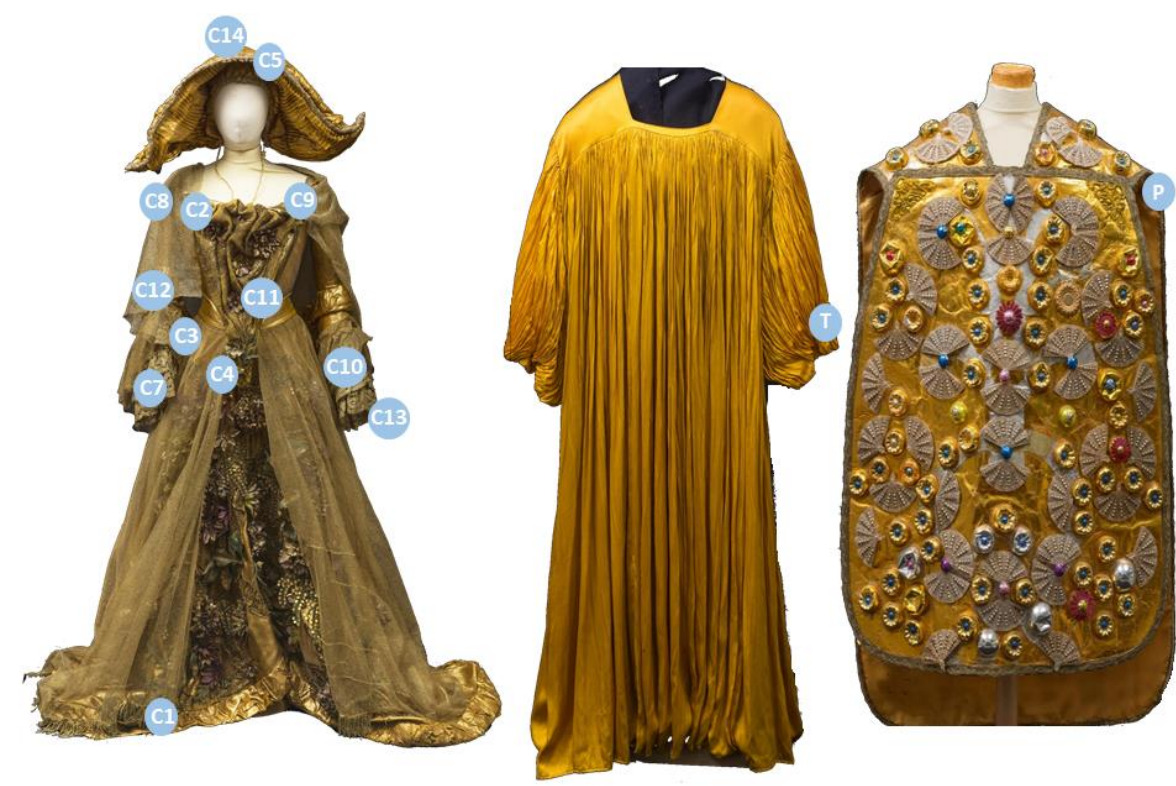

Figure 1. The "golden lady" costume in "Il Casanova" (left); tunic (center) and chasuble (right) of a bishop in "Roma." The sampling locations are labeled in light blue.

\subsection{Optical Microscope}

A Zeiss Axio Imager A1 optical microscope was used with $10 \times$ to $50 \times$ objective magnification, equipped with both a halogen and HBO UV lamps.

\subsection{ATR-FTIR}

ATR-FTIR spectra were collected using a Perkin Elmer Spectrum 100 spectrometer coupled with a MIRacle TM ATR accessory equipped with a SeZn crystal. Sixteen scans were collected from 4000 to $650 \mathrm{~cm}^{-1}$, with a resolution of $4 \mathrm{~cm}^{-1}$. Jasco Spectra Manager software was used for data analysis.

\subsection{SEM-EDX}

Metal threads were examined with an $\mathrm{EVO}^{\circledR}$ MA 25 scanning electron microscope (Zeiss, Germany) using the secondary electron detector (SE). Elemental analysis was performed with an EDS X-MAX $80 \mathrm{~mm}^{2}$ Energy-Dispersive X-ray probe on selected spots, or areas in case of bigger samples, using AZtec ${ }^{\circledR}$ software (Oxford Instruments, Abingdon, UK). SEM has a $3.0 \mathrm{~nm}$ resolution in high vacuum mode and all the systems operated under variable pressure vacuum (30 Pa). Morphology analyses were carried out using $10 \mathrm{kV}$ accelerating voltage, while the elemental ones using $20 \mathrm{kV}$ voltage at $8.5 \mathrm{~mm}$ working distance. The samples, either unaltered or as cross-sections resin-embedded and polished, were mounted on aluminum stubs with conductive tapes, and a gold coating was applied.

\section{5. $P y-G C / M S$}

The analyses were performed using a multi-shot pyrolyzer EGA/PY-3030D (Frontier Lab, Koriyama, Japan) coupled with a $6890 \mathrm{~N}$ gas chromatography system with a split/splitless injection port and a 5973 mass selective single quadrupole mass spectrometer (Agilent Technologies, Santa Clara, CA, USA).

The samples were placed in stainless steel cups. The Py furnace was set at $600{ }^{\circ} \mathrm{C}$ with the Py-GC interface at $280^{\circ} \mathrm{C}$. The GC injector temperature was $280^{\circ} \mathrm{C}$. The GC injection was operating in split mode and the best analytical results were obtained with a split ratio of 1:10. The chromatographic separation of pyrolysis products was performed on a fused silica capillary column HP-5MS (5\% diphenyl-95\% dimethyl-polysiloxane, $30 \mathrm{~m} \times 0.25 \mathrm{~mm}$ i.d., $0.25 \mu \mathrm{m}$ film thickness, J\&W Scientific, Agilent Technologies), preceded by $2 \mathrm{~m}$ of deactivated fused silica pre-column with internal diameter of $0.32 \mathrm{~mm}$. The chromatographic 
conditions were: $40^{\circ} \mathrm{C}$ for $5 \mathrm{~min}$ and $10{ }^{\circ} \mathrm{C} / \mathrm{min}$ to $310{ }^{\circ} \mathrm{C}$ for $20 \mathrm{~min}$. The helium (purity $99.9995 \%$ ) gas flow was set in constant flow mode at $1.2 \mathrm{~mL} / \mathrm{min}$.

MS parameters: electron impact ionization $(\mathrm{EI}, 70 \mathrm{eV})$ in positive mode; ion source temperature $230^{\circ} \mathrm{C}$; scan range $50-700 \mathrm{~m} / \mathrm{z}$; interface temperature $280^{\circ} \mathrm{C}$. Perfluorotributylamine (PFTBA) was used for mass spectrometer tuning. MSD ChemStation (Agilent Technologies) software was used for data analysis and peak assignment was based on a comparison with libraries of mass spectra (NIST 8.0).

\subsection{HPLC Analyses}

\subsubsection{Sample Pretreatment}

The extraction of dyes was performed following two different approaches. The yellowcolored fibers were extracted with a quick and effective dimethyl sulfoxide (DMSO, J.T. Baker, Deventer, The Netherlands), effective for most classes of dyes: the sample was added with $500 \mu \mathrm{L}$ of DMSO, followed by sonication (ultrasonic bath Sonorex Supra 10P, Bandelin Electronics, Germany) for $10 \mathrm{~min}$ at $60^{\circ} \mathrm{C}$, filtration with PTFE filters and injection in the HPLC systems.

The second approach, particularly suitable for extracting triarylmethine dyes from the fibers, was based on an oxalic acid extraction [41]: the filament was added with $0.5 \mathrm{M}$ oxalic acid/methanol/acetone/water solution (1:30:30:40 v/v/v/v), followed by sonication for $30 \mathrm{~min}$ at $60^{\circ} \mathrm{C}$. The filament was then removed from the extraction solvent and subjected to the extraction with DMSO reported above, while the extraction mixture was dried under nitrogen steam, and re-dissolved in $200 \mu \mathrm{L}$ of DMSO. The two extracts were filtered, admixed, and injected in the HPLC systems.

\subsubsection{HPLC Conditions}

For the HPLC-DAD analyses, the chromatographic system consisted of a PU-2089 quaternary pump equipped with a degasser, an AS-950 autosampler, and an MD-2010 spectrophotometric diode array detector (all modules are Jasco International Co., Tokyo, Japan). The software used for the analysis was ChromNav (Jasco International). The diode array detector (DAD) acquisition was performed in the range of 200-650 nm every $0.8 \mathrm{~s}$ with $4 \mathrm{~nm}$ resolution.

For the HPLC-MS analysis the system consisted of HPLC 1200 Infinity, coupled with a quadrupole-time of flight mass spectrometer Infinity Q-ToF 6530 detector by a Jet Stream ESI interface (Agilent Technologies). The ESI conditions were: drying and sheath gas $\mathrm{N}_{2}$, purity $>98 \%$, temperature $350^{\circ} \mathrm{C}$, flow $10 \mathrm{~L} / \mathrm{min}$ and temperature $375^{\circ} \mathrm{C}$, flow $11 \mathrm{~L} / \mathrm{min}$, respectively; capillary voltage $4.5 \mathrm{KV}$; nebulizer gas pressure $241 \mathrm{kPa}$. The fragmentor voltage was $175 \mathrm{~V}$; nozzle, skimmer and octapole RF voltages were set at $1000 \mathrm{~V}, 65 \mathrm{~V}$ and $750 \mathrm{~V}$, respectively. The high-resolution MS and MS/MS acquisition range was set from 100 to $1000 \mathrm{~m} / \mathrm{z}$ in negative and positive mode, with acquisition rate $1.04 \mathrm{spectra} / \mathrm{sec}$. For the MS/MS experiments, $30 \mathrm{~V}$ were applied in the collision cell to obtain CID fragmentation (collision gas $\mathrm{N}_{2}$, purity $99.999 \%$ ). The quadrupole mass bandpass used during MS/MS precursor isolation was $4 \mathrm{~m} / \mathrm{z}$ (mass to charge ratio). The Agilent tuning mix HP0321 was used daily to calibrate the mass axis.

The eluents used for the HPLC-DAD analyses were water and acetonitrile (ACN), both HPLC grade (Sigma-Aldrich, St. Louis, MO, USA), while the eluents for HPHPLCESI-Q-ToF analyses were water and acetonitrile, both LC-MS grade (Sigma-Aldrich, St. Louis, MO, USA). All eluents were added with $0.1 \% v / v$ formic acid (FA; $98 \%$ purity, J.T. Baker, USA).

For both systems, the chromatographic separation was performed on an analytical reversed-phase column Poroshell 120 EC-C18 $(3.0 \mathrm{~mm} \times 75 \mathrm{~mm}$, particle size $2.7 \mu \mathrm{m})$ with a Zorbax pre-column $(4.6 \mathrm{~mm} \times 12.5 \mathrm{~mm}$, particle size $5 \mu \mathrm{m})$, both Agilent Technologies. The flow rate was $0.4 \mathrm{~mL} / \mathrm{min}$ and the program was: $15 \% \mathrm{~B}(0.1 \% \mathrm{FA}$ in $\mathrm{ACN})$ for $2.6 \mathrm{~min}$, then to $50 \%$ B in $13.0 \mathrm{~min}$, to $70 \% \mathrm{~B}$ in $5.2 \mathrm{~min}$, to $100 \% \mathrm{~B}$ in $0.5 \mathrm{~min}$ and then held for 
$6.7 \mathrm{~min}$. Re-equilibration took $11 \mathrm{~min}$. During the separation, the column was kept at $30^{\circ} \mathrm{C}$.

\section{Results}

\section{1. "Il Casanova"}

The most significant results obtained on a selection of samples from the scene costume of the "golden lady" in "Il Casanova" are reported in the following paragraph. The detailed attribution of the peaks identified in the FT-IR spectra (Figure 2) and pyrograms (Figure 3a-e) is reported in Tables 1 and 2, respectively.

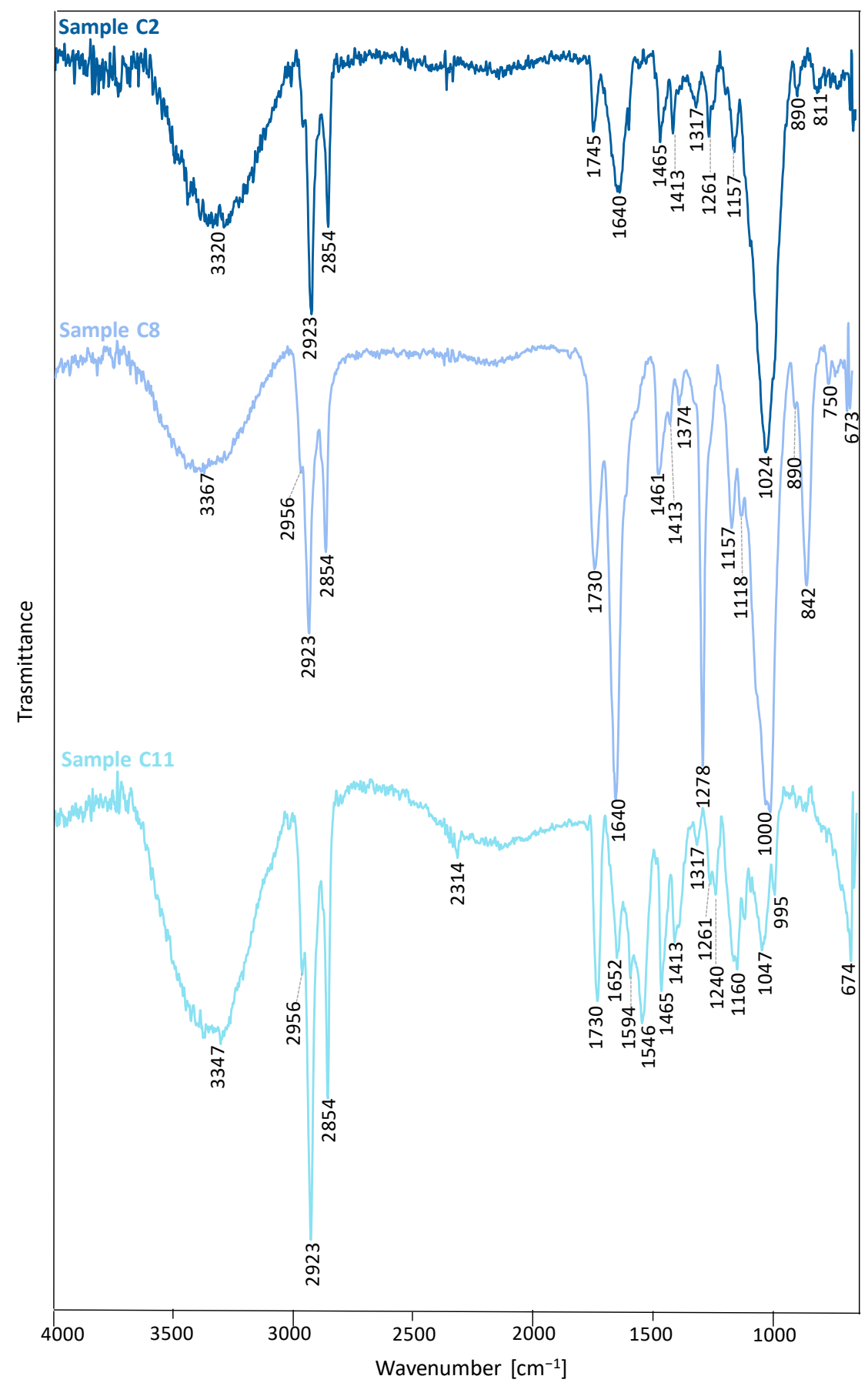

Figure 2. Attenuated Total Reflection- Fourier Transform Infrared (ATR-FTIR) spectra acquired for samples C2, C8, and C11 (from top to bottom). 
(a)

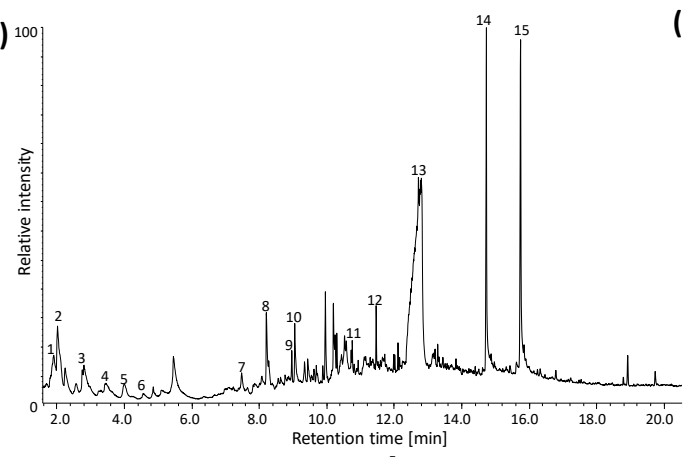

(c) ${ }^{10}$

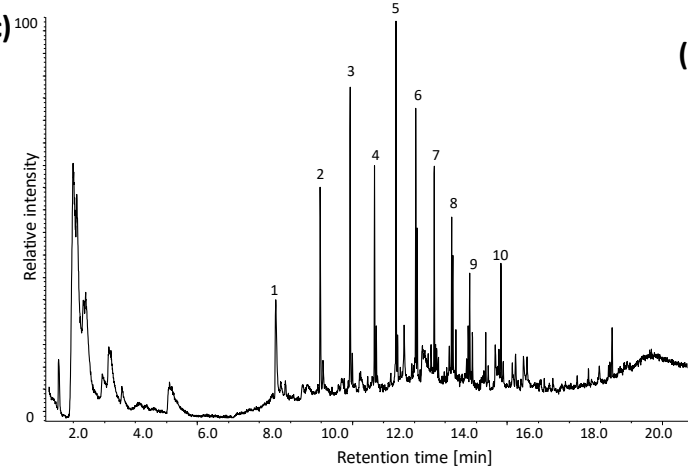

(b) 100

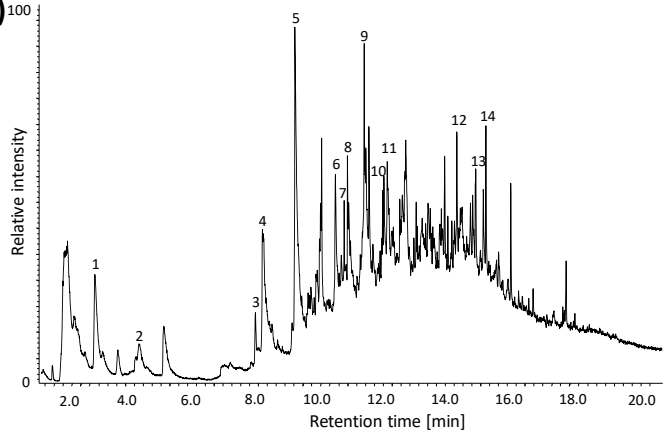

(d) ${ }^{10}$

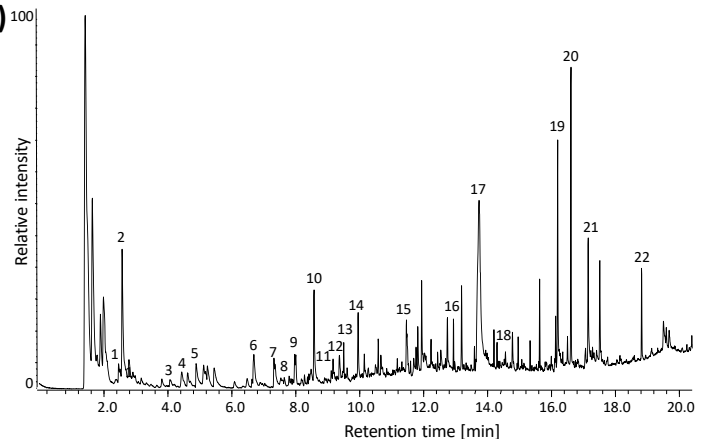

(e)

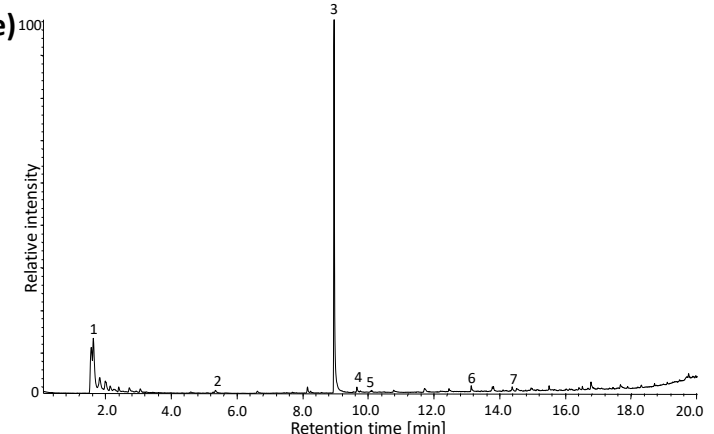

Figure 3. Pyrolysis Gas Chromatography Mass Spectrometry (Py-GC/MS ) pyrograms acquired for samples (a) C2, (b) C5, (c) $\mathrm{C} 7,(\mathbf{d}) \mathrm{C} 8$, and (e) $\mathrm{C} 11$.

The samples from the warp (sample C1) and from the black lace applied on the neckline of the costume (sample C2) were both identified as viscose upon OM observation. The polysaccharide nature of the sample was highlighted by the infrared spectrum (Figure 2, IR spectrum of C2), showing an intense broad absorption band centered at $1024 \mathrm{~cm}^{-1}$ (due to in-plane C-H bending of the ring) ascribable to carbohydrates [13,16,42]. The pyrolytic profile was mainly characterized by levoglucosan (labeled as \#13 in Figure 3a for sample C2), furfural and furan derivatives (labeled as 1-12), which are characteristic pyrolysis product of a polysaccharide material [43]. The yellow hue of the warp is due to azoic dye Direct Yellow 28 (DY28; C.I. 19555; $\mathrm{C}_{28} \mathrm{H}_{20} \mathrm{~N}_{4} \mathrm{O}_{6} \mathrm{~S}_{4}$ ), also detected in the yellow fiber of the volant and the lace applied on the sleeve (C3 and C7) and the corset (C4) (representative chromatograms will be shown in Section 3.2 for sample P). C3 and C4 were identified as cotton upon $\mathrm{OM}$ inspection. The difference between artificial fibers such as viscose (samples $\mathrm{C} 1$ and $\mathrm{C} 2$ ) and natural cotton fibers (samples $\mathrm{C} 3$ and $\mathrm{C} 4$ ) is clearly visible also in the SEM morphological images (both OM and SEM images are reported in Figure S1, Supplementary Materials).

The black hue of the lace is due to the use of dyes possibly belonging to the dioxazine family, as highlighted by the base peak in the mass spectra. The chemical formula corresponding to of the dioxazine dye used has not identified yet. These black dyes are composed of heterocyclic compounds and were first synthetized in 1928 [44]. 
The FT-IR spectrum (data not reported) obtained on the sample from the decoration of the hat (sample C5) is in good agreement with that of reference silk, showing the absorption bands associated to amide I (1650-1600 $\left.\mathrm{cm}^{-1}\right)$ and amide II (1550-1515 $\left.\mathrm{cm}^{-1}\right)$ [45], suggesting the presence of proteins. Moreover, the absence of any significant absorption band characteristic of carbonyl groups ruled out the presence of any other synthetic material, such as polyamides. The Py-GC/MS analysis (Figure 3b) confirmed the assignment by providing a profile typical of a protein material featuring aromatic hydrocarbons (labeled as \#1-5), phenols and alkylphenol derivatives (labeled as 5-9), and diketopiperazines (DKP, labeled as \#12-14) [46]. The high sensitivity of HPLC-ESI-Q-ToF was exploited for determining the dye responsible for the violet hue of the decoration on the lady's hat. The Extract Ion Chromatograms acquired in positive mode ionization (Figure S2, Supplementary Materials) showed the presence of two triarylmethine compounds, penta$N$-methyl pararosaniline and hexa- $N$-methyl pararosaniline, identified on the basis of the product-ion spectra reported in the literature [47]. The use of a crystal violet (C.I. 42555) formulation is, thus, very plausible since triarylmethines were and still are widely used in the textile industry [48]. Traces of crystal violet due to contamination were also highlighted in the samples from the warp (sample C1), the volant applied on the sleeve (sample C3), and the corset (sample C4).

The Py-GC/MS chromatogram of the sample collected from the golden lace of the sleeve (sample C7) featured aliphatic hydrocarbons with a chain length from 10 up to 20 carbon atoms (labeled as \#1-10 in Figure 3c). These species can be related to a fiber based on a polyolefin polymer, probably polyethylene [49].

Lamé and metal threads were also analyzed to inquire why their state of conservation is very different in terms of color change and delamination processes (Figure 4 and Figures S3-S5, Supplementary Materials). The metal foils used as lamé or wrapped around fibers or even as solid metal strips were made of $\mathrm{Al}$, or $\mathrm{Cu} / \mathrm{Zn}$ or $\mathrm{Cu} / \mathrm{Ag}$ alloys, as reported in detail in Table 5. Both copper-containing foils present signals due to chlorine, whose presence may be ascribed to the atmospheric environment or to the cleaning methods, as already observed for historical metal threads [6,50] (see Figures S4 and S5, Supplementary Materials). FTIR and/or Py-GC/MS were also applied, as detailed in the following paragraphs, to verify the nature of possible synthetic polymers applied as support of metal foils, or as varnishes/lacquers. The presence of synthetic polymers was suggested both by visual inspection under the OM and SEM morphological analyses. For all samples, the presence of a synthetic layer was verified by FTIR. This finding is consistent with literature data [51], describing 20th century metal threads made of Al, or Ag or Au blends, lacquered with a synthetic material or even trapped (as a sandwich) between two polyester or Cellophane polymer layers.

Samples C8, C9, C10, C12, and C13 all featured a sandwich-like structure (OM and SEM images are provided for sample C10 as an example in Figure $4 \mathrm{a}-\mathrm{c}$ ). The infrared spectrum acquired for sample C8 (Figure 2), from the corset lamé fabric, was characterized by a broad band around $1000 \mathrm{~cm}^{-1}$, less intense and wider than that acquired for sample $\mathrm{C} 2$, but still referable to carbohydrates. The spectrum also featured the absorption band typical of carbonyl groups at $1730 \mathrm{~cm}^{-1}$, while the asymmetric and symmetric stretching of methylene groups (2956-2923 $\mathrm{cm}^{-1}$ and $28 \mathrm{~cm}^{-1}$ ) show relatively higher intensities with respect to the pure viscose, suggesting the presence of a polyester $[9,52,53]$. Even if the spectra showed the presence of bands compatible with cellulose nitrate, the absence in the pyrolysis products of all the characteristic additives of this materials, such as triphenyl phosphate or diisononyl phthalate, allowed us to exclude the presence of such a material. These bands are, thus, associated to external contamination. 

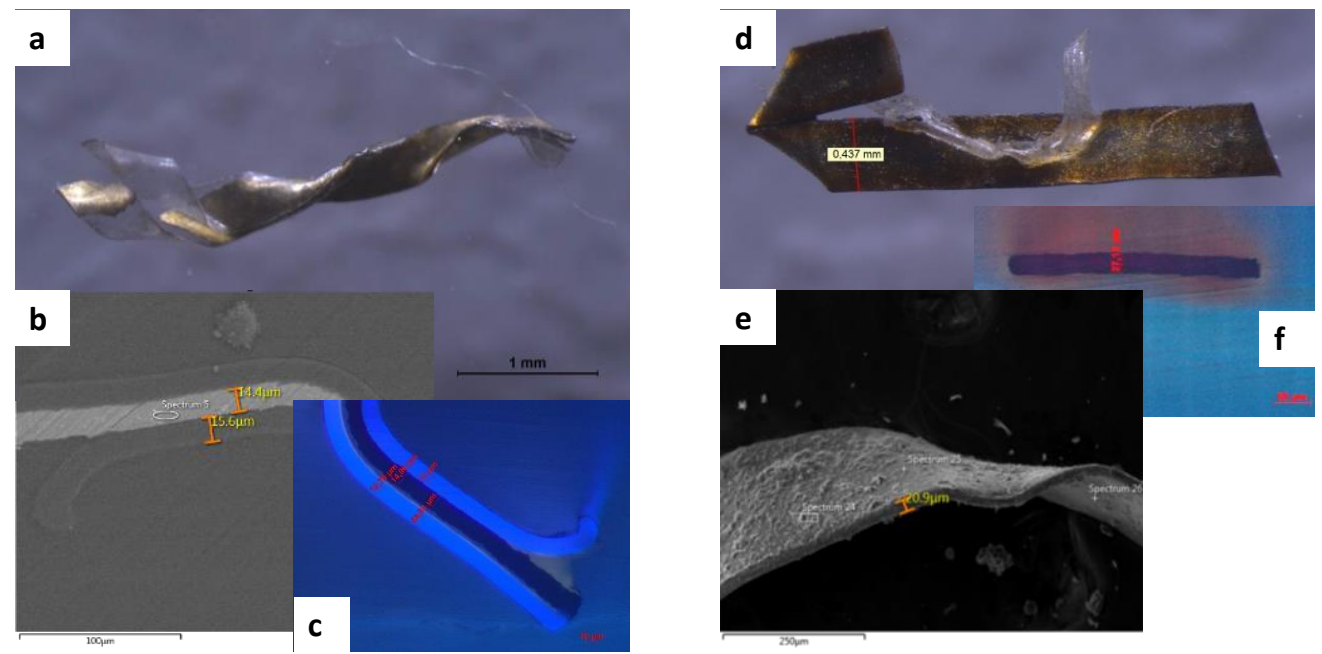

Figure 4. Different types of metal threads: (a) photograph of sample C10 under the optical microscope, $18 \times$; (b) SEM image of the cross section of sample C10; (c) photograph under UV light of the cross section of sample C10, 20×; (d) photograph of sample C14 under the optical microscope, 18 $\times$; (e) SEM image of a side view of sample C14; (f) photograph under UV light of the cross section of sample C14, $10 \times$.

The hypothesized co-presence of viscose and polyester was confirmed by the interpretation of the pyrolytic profile. The presence in the Py-GC/MS chromatogram of furfural ad furan derivatives (labeled as \#3, \#6, \#11-13 and \#15 in Figure 3d) allowed us to identify the polysaccharide material specifically as viscose, while the presence of benzene (\#1), toluene (\#4), 1,2-dimethylbenzene (\#7), styrene (\#9), phthalic anhydride (\#16), and several plasticizers, with diethyl and bis(2-ethylhexyl) phthalate (\#18 and \#22) as the most abundant, and the absence of any pyrolysis product associated to other binders, as an alkyd resin, could be related to the pyrolysis of a polyester [49]. The absence of glycerin ruled out the possible presence of Cellophane, a material made of regenerated cellulose in which glycerin is added for softening [54]. The co-presence of polyester and viscose can be interpreted by hypothesizing the use of polyester as embedding material for the metallic foil and the presence of viscose as contamination from the textile background underneath the lamé (see the photograph of the corset detail in Figure S3a, Supplementary Materials).

The same composition was assessed by FTIR for sample C9 (golden foil in the lace applied on the right side of the neckline) and sample C12 (used in the trimming on the left side of the neckline), both showing a sandwich-like structure where polyester is the embedding material. While for sample C9, the presence of viscose is due to the core of the metal thread, for sample $\mathrm{C} 12$, it is most probably due to the sewing thread.

Samples C10 and C13, from the volant and the lace applied on the left sleeve, respectively, only contained polyester accordingly to FTIR data, besides the aluminum foil. In this case, the embedded metal foil was directly interwoven with other fibers to build up the textile.

The sample from the golden lamé (Figure S4, Supplementary Materials) on the corset decoration (sample C11) presented a different appearance, since only the metallic leaf was visible under the microscope and SEM morphological analysis, while no polymeric layer was evident. The metallic leaf is composed of copper and zinc. The uneven presence of chlorinated compounds on the metal layer was highlighted by SEM with elemental analysis (Figure S5c, Supplementary Materials). Both spectroscopic and pyrolysis-based analyses point to an acrylic polymer as a varnish applied on the metal foil. The intense bands ascribable to $\mathrm{C}-\mathrm{O}\left(1261 \mathrm{~cm}^{-1}\right.$ and $\left.1047 \mathrm{~cm}^{-1}\right), \mathrm{C}-\mathrm{O}-\mathrm{C}$ asymmetric and symmetric stretching $\left(1240 \mathrm{~cm}^{-1}\right.$ and $\left.1160 \mathrm{~cm}^{-1}\right)$, and $\mathrm{C}=\mathrm{O}\left(1730 \mathrm{~cm}^{-1}\right)$ typical of molecules containing ester groups are consistent with an acrylic polymer $[52,55]$. The pyrolytic profile highlighted the 
presence of a polymer based on n-butylmethylacrylate (identified due to an intense peak at $t_{R}=9.0 \mathrm{~min}$ and labeled as \#3 in Figure 3e) [49].

An acrylic resin was also used to varnish sample C14, made of silver and copper (decoration of the hat, interwoven with a black thread, Figure S5b, Supplementary Materials). The observation under the microscope also highlighted the delamination of the varnish from the metallic layer (Figure $4 \mathrm{~d}-\mathrm{f}$ ). The high quality of the metal blend is consistent with that of the black thread used for the decoration of the hat, which was made of silk (sample C5).

Table 1. Band assignment for the Attenuated Total Reflection- Fourier Transform Infrared (ATR-FTIR) spectra of samples $\mathrm{C} 2, \mathrm{C} 8$, and $\mathrm{C} 11$ reported in Figure 2.

\begin{tabular}{|c|c|c|c|}
\hline Wavenumber $\left(\mathrm{cm}^{-1}\right)$ & Vibrational Modes & Wavenumber $\left(\mathrm{cm}^{-1}\right)$ & Vibrational Modes \\
\hline \multicolumn{2}{|r|}{ Sample C2 } & \multicolumn{2}{|c|}{ Sample C11 } \\
\hline 3320 & $v \mathrm{OH}$ & 3347 & $v_{\mathrm{OH}}$ \\
\hline 2923 & $v_{\mathrm{a}} \mathrm{CH}_{2}$ & 2956,2923 & $v_{\mathrm{a}} \mathrm{CH}_{2}$ \\
\hline 2854 & $v_{\mathrm{s}} \mathrm{CH}_{2}$ & 2854 & $v_{\mathrm{s}} \mathrm{CH}_{2}$ \\
\hline 1745 & $v \mathrm{C}=\mathrm{O}$ & 2314 & superior harmonic of $\mathrm{NH}$ \\
\hline 1640 & $\delta \mathrm{OH}$ (bound water) & 1730 & $v \mathrm{C}=\mathrm{O}$ \\
\hline 1465,1317 & $v \mathrm{C}-\mathrm{C}$ (aromatic ring) & 1652 & $\delta \mathrm{OH}$ (bound water) \\
\hline 1413 & $\delta_{\mathrm{a}} \mathrm{CH}_{2}$ (in-plane), $\delta_{\mathrm{a}} \mathrm{C}-\mathrm{O}-\mathrm{H}$ & $1594,1546,1465$ & $v \mathrm{C}-\mathrm{C}$ (aromatic ring) \\
\hline 1261,1157 & $v \mathrm{C}-\mathrm{O}$ & 1413 & $\delta \mathrm{CH}_{2}$ (in-plane, aromatic ring) \\
\hline 1027 & $\delta \mathrm{CH}$ (in-plane, aromatic ring) & 1317 & $\vee C-C$ \\
\hline \multirow[t]{2}{*}{890,811} & $\delta \mathrm{CH}$ (out-of-plane, aromatic ring) & 1261 & $v \mathrm{C}-\mathrm{O}$ \\
\hline & Sample C8 & 1240 & $v_{\mathrm{a}} \mathrm{C}-\mathrm{C}-\mathrm{O}$ \\
\hline 3367 & $v \mathrm{OH}$ & 1160 & $v_{a} \mathrm{C}-\mathrm{O}-\mathrm{C}$ \\
\hline 2956,2923 & $v_{\mathrm{a}} \mathrm{CH}_{2}$ & 1047 & $v \mathrm{C}-\mathrm{O}$ \\
\hline 2854 & $v_{\mathrm{S}} \mathrm{CH}_{2}$ & 995 & $\delta \mathrm{CH}$ (in-plane, aromatic ring) \\
\hline 1730 & $v \mathrm{C}=\mathrm{O}$ & 674 & $\delta \mathrm{CH}$ (out-of-plane, aromatic ring) \\
\hline 1640 & $\delta \mathrm{OH}$ (bound water) & & \\
\hline 1461,1413 & $\delta_{\mathrm{a}} \mathrm{CH}_{2}$ (in-plane) & & \\
\hline 1374 & $\delta \mathrm{CH}$ & & \\
\hline $1278,1157,1118$ & $v \mathrm{C}-\mathrm{O}$ & & \\
\hline $995,890,842$ & $\delta \mathrm{CH}$ (out-of-plane, aromatic ring) & & \\
\hline 750,673 & $\omega \mathrm{C}-\mathrm{H}$ (aromatic ring) & & \\
\hline 842 & $\delta \mathrm{C}-\mathrm{O}-\mathrm{H}$ & & \\
\hline 723 & $v \mathrm{C}-\mathrm{O}$ & & \\
\hline
\end{tabular}

Table 2. Main pyrolysis products detected in the pyrograms of samples C2, C5, C7, C8, and C11 reported in Figure 3a-e. The most intense peaks are reported in bold.

\begin{tabular}{|c|c|c|c|c|}
\hline & $\#$ & $\operatorname{tr}(\min )$ & Compound & Mass Spectra \\
\hline \multirow{15}{*}{ Sample C2 } & 1 & 1.5 & 2,5-dimethylfuran & $\mathbf{9 6}, 91, \mathbf{8 1}, 67,53,43,39$ \\
\hline & 2 & 1.9 & 5-methyl-2,3-dihydrofuran & $84,69,56,41$ \\
\hline & 3 & 2.7 & 2-cyclopentenone & $82,78,54,39,28$ \\
\hline & 4 & 3.5 & Furfuryl alcohol & $\mathbf{9 8}, 8170,53,41$ \\
\hline & 5 & 4.0 & 2-methylfuran & $96,81,67,53,39$ \\
\hline & 6 & 4.2 & 2-ethylfuran & $82,53,39,27$ \\
\hline & 7 & 7.7 & Furfuryl acetate & $140,98, \mathbf{8 1}, 52,43$ \\
\hline & 8 & 8.4 & 2,4-dimethylfuran & $\mathbf{9 6}, \mathbf{8 1}, 67,53,41,39$ \\
\hline & 9 & 9.3 & 5-methylfurfural & $\mathbf{1 1 0}, 95, \mathbf{8 1}, \mathbf{5 3}, 43,39$ \\
\hline & 10 & 9.5 & 5-methyl-2(5H)-furanone & $98,83,69,53,41$ \\
\hline & 11 & 10.9 & 5-acetoxymethyl-2-furaldehyde & $168,126,109,97,79,69,53,43$ \\
\hline & 12 & 11.7 & 2,5-dihydrofuran & $\mathbf{7 0}, 51, \mathbf{4 1}, 39$ \\
\hline & 13 & 12.7 & Levoglucosan & $162,98,85,73,60,57,43,31,29$ \\
\hline & 14 & 14.7 & Palmitic acid & $256,213,129,73,60,43$ \\
\hline & 15 & 15.7 & Stearic acid & $284,241,185,129,111,97,85,73,57,43$ \\
\hline
\end{tabular}


Table 2. Cont.

\begin{tabular}{|c|c|c|c|c|}
\hline & $\#$ & $\operatorname{tr}(\min )$ & Compound & Mass Spectra \\
\hline \multirow{14}{*}{ Sample C5 } & 1 & 2.7 & Benzene & $78,63,52,39$ \\
\hline & 2 & 4.6 & Toluene & $\mathbf{9 2}, 65,51,39$ \\
\hline & 3 & 7.8 & Ethylbenzene & $106,91,77,65,51,39$ \\
\hline & 4 & 8.1 & Styrene & $104,89,78,63,51,39$ \\
\hline & 5 & 9.6 & Phenol & $94,66,55,39$ \\
\hline & 6 & 10.4 & 2-methylphenol & $108,90,79,63,51,40$ \\
\hline & 7 & 10.6 & 4-methylphenol & $108,90,77,63,51,39$ \\
\hline & 8 & 10.7 & 3-methylphenol & $108,90,77,63,53,41$ \\
\hline & 9 & 11.4 & 4-ethylphenol & $122,107,91,77,65,51,39$ \\
\hline & 10 & 12.3 & 3-vinylbenzene & $192,177,161,151,91,73,65$ \\
\hline & 11 & 12.4 & Indole & $117,90,63,50,39$ \\
\hline & 12 & 15.5 & DPK-1 & $154,125,86,70,55,41$ \\
\hline & 13 & 15.2 & DPK-2 & $154,125,73,60,43$ \\
\hline & 14 & 15.4 & DPK-3 & $221,194,154,125,70,41$ \\
\hline \multirow{10}{*}{ Sample C7 } & 1 & 7.5 & 1-decene & $140, \mathbf{1 1 1}, \mathbf{9 7}, 83,70,56,41$ \\
\hline & 2 & 9.0 & 1-undecene & $154,139, \mathbf{1 1 1}, \mathbf{9 7}, 83,70,55,41$ \\
\hline & 3 & 9.9 & 1-dodecene & $168,153, \mathbf{1 1 1}, \mathbf{9 7}, 83,69,55$ \\
\hline & 4 & 10,8 & 1-tridecene & $182,167,154, \mathbf{1 1 1}, \mathbf{9 7}, 83,69,55,41$ \\
\hline & 5 & 11.5 & 1-tetradecene & $\mathbf{1 9 6}, 182,167,154, \mathbf{1 1 1}, \mathbf{9 7}, 83,69,55,41$ \\
\hline & 6 & 12.1 & 1-hexadecene & $224,210,196,182,167,154, \mathbf{1 1 1}, 97,83,695541$ \\
\hline & 7 & 12.7 & 1-eptadecene & $238,196,182,167,154, \mathbf{1 1 1}, \mathbf{9 7}, 83,69,55,41$ \\
\hline & 8 & 13.3 & 1-octadecene & $252,224,196,182,167,154, \mathbf{1 1 1}, \mathbf{9 7}, 83,69,55,41$ \\
\hline & 9 & 13.8 & 1-nonadecene & $266,238,196,182,167,154,111,97,83,69,55,41$ \\
\hline & 10 & 14.9 & 1-undecene & $280,252,196,182,167,154,111,97,83,69,55,41$ \\
\hline \multirow{22}{*}{ Sample C8 } & 1 & 2.7 & Benzene & $78,63,52,39$ \\
\hline & 2 & 2.8 & Hydroxyacetone & $74,58,43$ \\
\hline & 3 & 4.2 & 2-methylfuran & $82,53,39,27$ \\
\hline & 4 & 4.6 & Toluene & $92,65,51,39$ \\
\hline & 5 & 5.0 & Allyl propryl ether & $100,71,58, \mathbf{4 1}, 27$ \\
\hline & 6 & 6.8 & Furfural & $96,67,39$ \\
\hline & 7 & 7.7 & 1,2-dimethylbenzene & $106,91,77,65,51,41$ \\
\hline & 8 & 7.8 & Furfuryl methyl ester & $\mathbf{1 1 2}, 95, \mathbf{8 1}, 53,39$ \\
\hline & 9 & 8.1 & Styrene & $104,89,78,63,51,39$ \\
\hline & 10 & 8.4 & 2-methyl-2-cyclopentenone & $96,81,67,53,39$ \\
\hline & 11 & 8.7 & Furfuryl alcohol & $98, \mathbf{8 1}, 69,53, \mathbf{4 1}, 38$ \\
\hline & 12 & 9.3 & 5-methylfurfural & $\mathbf{1 1 0}, 95, \mathbf{8 1}, \mathbf{5 3}, 43,39$ \\
\hline & 13 & 9.5 & 5-methyl-2(5H)-furanone & $98,83,69,53,41$ \\
\hline & 14 & 10.1 & 2-hydroxy-3-methyl-2-cyclopentenone & $112,97,83,69,55,41$ \\
\hline & 15 & 11.7 & 2,5-dihydrofuran & $\mathbf{7 0}, 51, \mathbf{4 1}, 39$ \\
\hline & 16 & 14.7 & Phthalic anhydride & $148, \mathbf{1 0 4}, \mathbf{7 6}, 61,50,38$ \\
\hline & 17 & 14.1 & Levoglucosan & $162,98,85,73,60,57,43,31,29$ \\
\hline & 18 & 14.7 & Diethyl phthalate & $222,177,149,132,121,105,93,76,65,50,45$ \\
\hline & 19 & 16.3 & Palmitic acid & $256,213,129,73,60,43$ \\
\hline & 20 & 16.4 & Didodecyl phthalate & $502,167,149,133,123,104,97,83,76,69,57$ \\
\hline & 21 & 17.3 & Stearic acid & $284,241,185,129,111,97,85,73,57,43$ \\
\hline & 22 & 14.7 & Bis(2-ethylhexyl) phthalate & $390,279,167,149,132,113,104,83,71,57,43$ \\
\hline \multirow{7}{*}{ Sample C11 } & 1 & 2.1 & 1-hexene & $84,69,56,41$ \\
\hline & 2 & 5.3 & 1-octene & $112,83,70,55,43$ \\
\hline & 3 & 9.0 & n-butyl methacrylate & $142,127,113,99,87,69,56$ \\
\hline & 4 & 9.6 & Decene & $168,153,140,126,111,97,83,69$ \\
\hline & 5 & 9.9 & 1-dodecene & $140, \mathbf{1 1 1}, \mathbf{9 7}, 83,70,56,41$ \\
\hline & 6 & 13.1 & 1-pentadecene & $210,182,154,140,125, \mathbf{1 1 1}, \mathbf{9 7}, 83,69,55,41$ \\
\hline & 7 & 14.4 & 1-hexadecene & $224,210,196,182,167,154,111,97,83,69$ \\
\hline
\end{tabular}




\section{2. "Roma"}

The combined approach based on ATR-FTIR and PY-GC/MS was applied for the identification of the fiber composition of the tunic and of the chasuble of the bishop. The detailed results obtained for these two samples are summarized in Table 5.

The spectroscopic and mass spectrometric analyses allowed us to identify the material used to produce the tunic as viscose (sample T). The HPLC-DAD chromatogram (Figure 5a) of the tunic sample featured three peaks absorbing at 330-390 nm; thus, in the yellow portion of the visible spectrum. The HPLC-ESI-Q-ToF (Figure $5 b$ ) allowed us to identify them as the azoic dye Direct Yellow 28 (DY28; C.I. 19555; $\mathrm{C}_{28} \mathrm{H}_{20} \mathrm{~N}_{4} \mathrm{O}_{6} \mathrm{~S}_{4}$ ), a possible DY28 oxidation product (labeled as $\mathrm{Ox} ; \mathrm{C}_{28} \mathrm{H}_{20} \mathrm{~N}_{4} \mathrm{O}_{7} \mathrm{~S}_{4}$ ), and a plausible synthesis byproduct (labeled as I; $\mathrm{C}_{28} \mathrm{H}_{18} \mathrm{~N}_{4} \mathrm{O}_{6} \mathrm{~S}_{4}$ ), on the bases of the molecular formula suggested by the Formula Generation feature of the software and interpretation of the tandem mass spectra. The oxidation product might have been generated by the heat applied to the tunic during the pleating treatment.
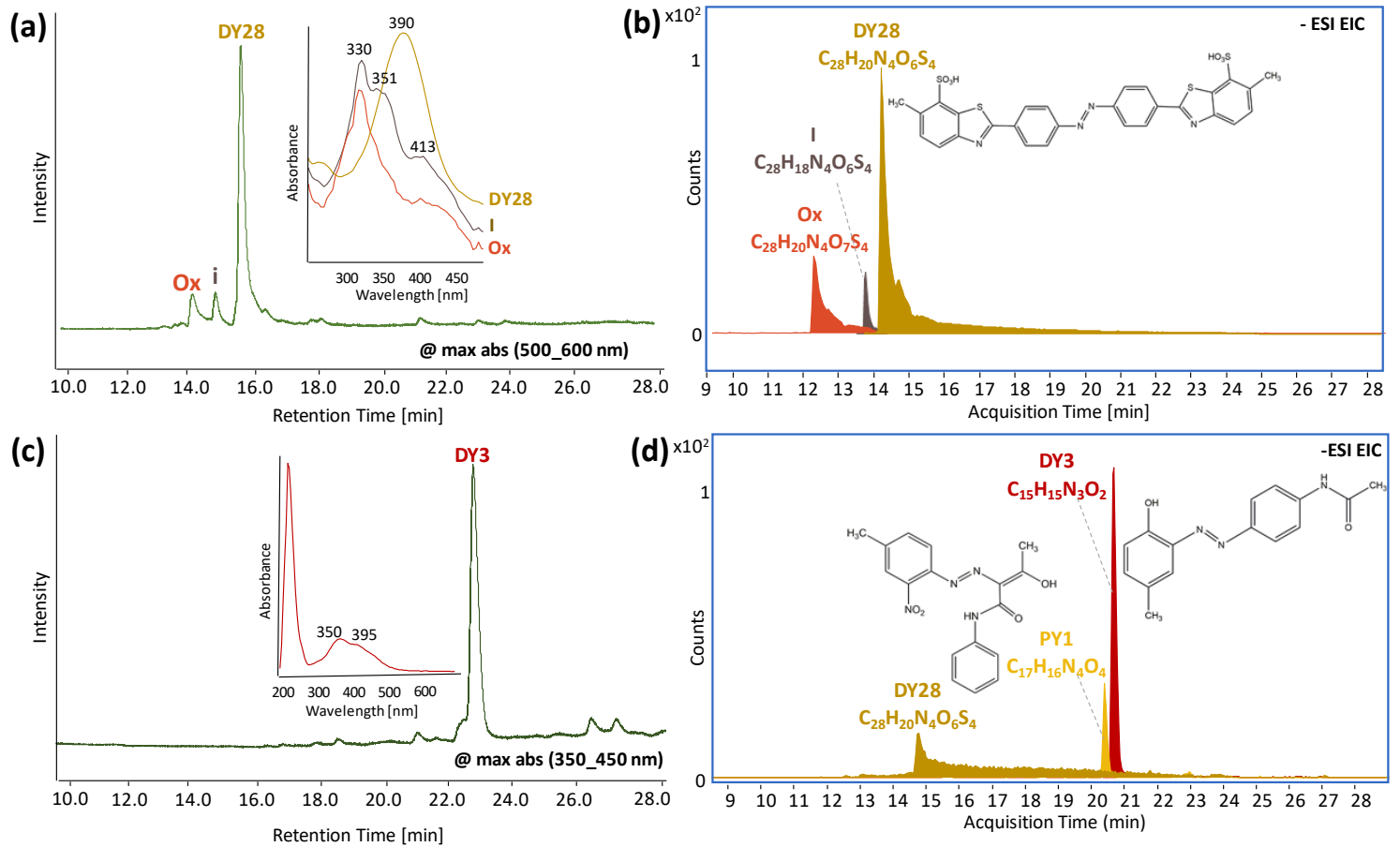

Figure 5. Sample T: (a) High Performance Liquid Chromatography with Diode Array Detector (HPLC-DAD) chromatogram acquired at max abs. 500-600 nm together with the UV-Vis spectrum of DY28, I, and Ox and (b) High Performance Liquid Chromatography with mass spectrometry detection (HPLC-ESI-MS) Extracted Ion Chromatograms (EIC) of $\mathrm{C}_{28} \mathrm{H}_{20} \mathrm{~N}_{4} \mathrm{O}_{7} \mathrm{~S}_{4}$, $\mathrm{C}_{28} \mathrm{H}_{18} \mathrm{~N}_{4} \mathrm{O}_{6} \mathrm{~S}_{4}$, and $\mathrm{C}_{28} \mathrm{H}_{20} \mathrm{~N}_{4} \mathrm{O}_{6} \mathrm{~S}_{4}$ (negative ionization mode). Sample P: (c) HPLC-DAD chromatogram acquired at max abs. 350-450 nm together with the UV-Vis spectrum of DY3 and (d) HPLC-ESI-Q-ToF EIC of $\mathrm{C}_{28} \mathrm{H}_{20} \mathrm{~N}_{4} \mathrm{O}_{6} \mathrm{~S}_{4}, \mathrm{C}_{17} \mathrm{H}_{16} \mathrm{~N}_{4} \mathrm{O}_{4}$, and $\mathrm{C}_{15} \mathrm{H}_{15} \mathrm{~N}_{3} \mathrm{O}_{2}$ (negative ionization mode).

The analyses allowed us to identify the material used for the fabric of the chasuble as Bemberg (sample P). Bemberg, the brand name for cuprammonium rayon, was patented in 1860 , and consists of an artificial fiber obtained by solubilizing cellulose in an ammoniac solution of copper (II) hydroxide [3]. Due to a lack of literature data regarding this material, the identification was only possible through the comparison of the Py-GC/MS and ATRFTIR results with those obtained for a reference Bemberg thread. In detail, the ATR-FTIR (Figure 6a) differs from that of viscose mainly because of the presence of an intense peak at $1222 \mathrm{~cm}^{-1}$, due to C-O-C asymmetric stretching, and lower peaks at $1434 \mathrm{~cm}^{-1}$ and $1367 \mathrm{~cm}^{-1}$ ascribable to $\mathrm{CH}_{2}$ bending and in-plane $\mathrm{C}-\mathrm{H}$ bending, respectively. The pyrogram was characterized by the presence of acetic acid (labeled as 1 in Figure $6 \mathrm{~b}$ ) as the main pyrolysis product, and several furfural ad furan derivatives (labeled as 3, 7, 
11, and 15). The profile was quite distinctive, thus enabling us to discriminate Bemberg from other polysaccharide-based fibers. The detailed attribution of the peaks identified in the FT-IR spectrum and in the pyrogram (Figure $6 a, b$ ) is reported in Tables 3 and 4 . The HPLC-DAD data (Figure 5c) suggested that the yellow hue of the chasuble was mainly due to the azoic dye Disperse Yellow 3 (DY3; C.I. 11855), commonly used since 1940 for dyeing synthetic fibers [56]. The application of HPLC-ESI-Q-ToF (Figure 5d) confirmed the use of DY3 $\left([\mathrm{M}-\mathrm{H}]^{-}=268.211\right)$, highlighting the presence of minor amounts of DY28 $\left([\mathrm{M}-\mathrm{H}]^{-}=635.017\right)$, already detected in sample T, and of a monoazo dye, namely Pigment Yellow 1 (PY1; C.I. 11680; $[\mathrm{M}-\mathrm{H}]^{-}=339.199$ ). Since the three dyes have rather different structures (Figure 5), it is plausible that they did not derive from a single formulation, but that the textile was subjected to consecutive dye baths with different dyes. Thanks to the interview given by Giuseppe Bruno Bossio to one of the authors [39], it is known that Danilo Donati often performed further dyeing processes on already-colored costumes and fabrics to obtain the desired shade. By comparing the results obtained on the different samples from the same costume, we can hypothesize that the fabric of both the tunic and the chasuble was originally dyed with DY28, and that the latter was afterwards over-dyed with PY1 and DY3. This hypothesis is consistent with the evidence collected during the cleaning tests performed prior to restoration: the chasuble bled when a very mild cleaning approach, entailing a hydroalcoholic solution, was employed, while no effect was observed for the tunic. The bleeding is probably due to the solubilization of DY3, which is soluble both in water and in ethanol [56], while PY1 is known to be highly photo-stable, and it is insoluble in alcoholic solution [44]. DY28 cannot be accounted responsible for the bleeding, since the tunic, dyed with DY28 only, did not show any color change after the treatment.
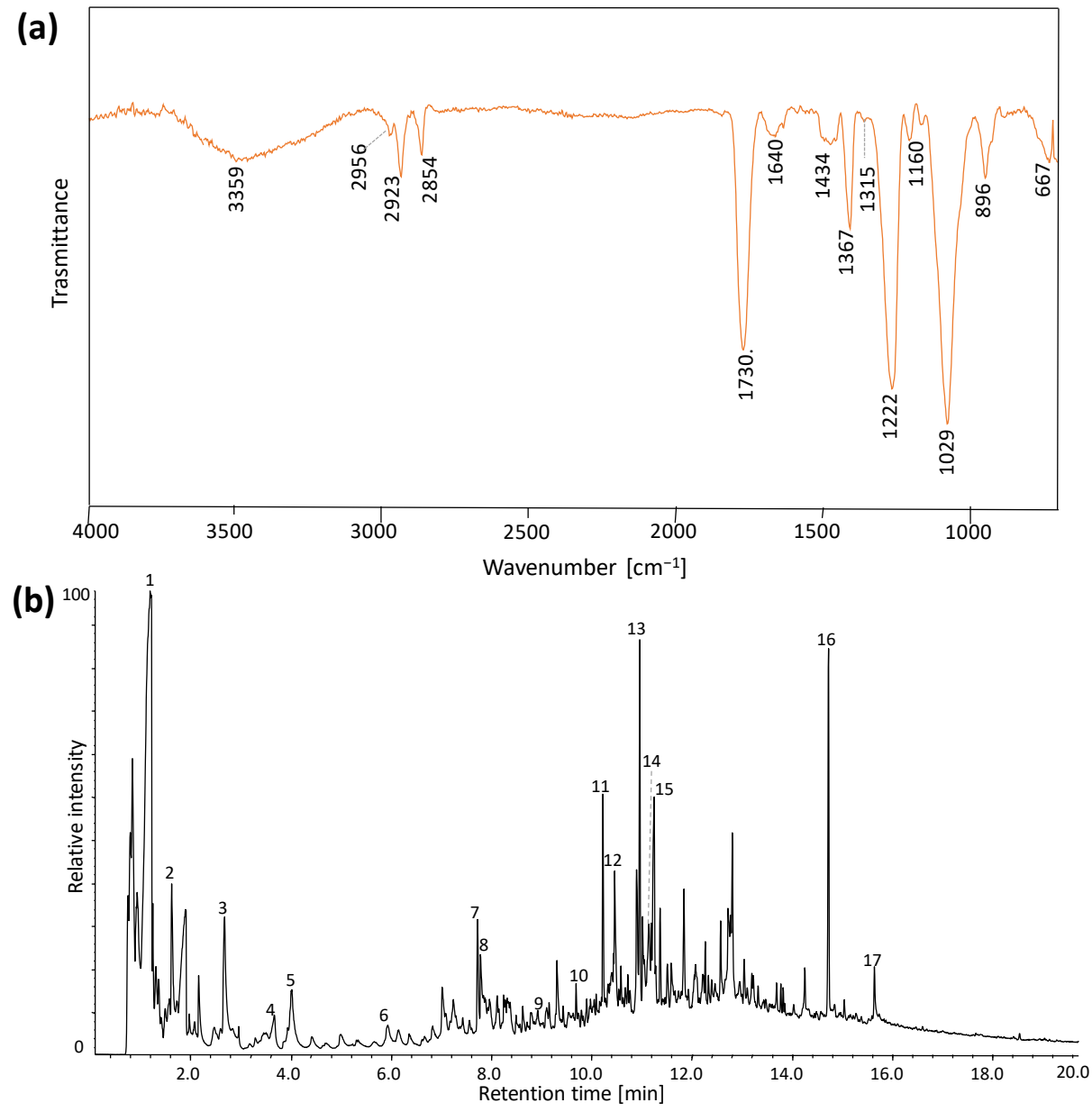

Figure 6. (a) ATR-FTIR spectrum and (b) Py-GC/MS pyrogram of sample P. 
Table 3. Band assignment for the ATR-FTIR spectrum of sample P reported in Figure 6a.

\begin{tabular}{ll}
\hline Wavenumber $\left(\mathbf{c m}^{-\mathbf{1}}\right)$ & Vibrational Modes \\
\hline 3359 & $v \mathrm{OH}$ \\
2956,2923 & $v_{\mathrm{a}} \mathrm{CH}_{2}$ \\
2852 & $v_{\mathrm{s}} \mathrm{CH}_{2}$ \\
1730 & $v \mathrm{C}=\mathrm{O}$ \\
1640 & $\delta \mathrm{OH}$ (bound water) \\
1434 & $\delta \mathrm{CH}$ \\
1367 & $\delta \mathrm{CH}($ in-plane, aromatic ring) \\
1315 & $\omega \mathrm{CH} \mathrm{H}_{2}$ \\
1222,1160 & $v \mathrm{C}-\mathrm{O}-\mathrm{C}$ \\
1029 & $v \mathrm{C}-\mathrm{O}, v \mathrm{C}-\mathrm{C}$ and C-H (ring and side group) \\
896 & $v \mathrm{C}-\mathrm{C}-\mathrm{H}$ (deformation of aromatic ring) \\
667 & $\delta \mathrm{C}-\mathrm{OH}$ (out-of-plane) \\
\hline
\end{tabular}

Table 4. Main pyrolysis products detected in the pyrogram of sample P reported in Figure $6 \mathrm{~b}$. The most intense peaks are reported in bold.

\begin{tabular}{|c|c|c|c|}
\hline$\#$ & $\operatorname{tr}(\min )$ & Compound & Mass Spectra \\
\hline 1 & 1.2 & Acetic acid & $60,45,43$ \\
\hline 2 & 1.7 & 2-ciclopenten-1-one & $82,78,54,39,28$ \\
\hline 3 & 2.7 & 2-methylfuran & $82,53,39,27$ \\
\hline 4 & 3.6 & Acetoxy-2-propanone & $116,86,73,57$ \\
\hline 5 & 4.0 & 4-cyclopentene-1,3-dione & $96,68,54$ \\
\hline 6 & 5.9 & 1,3-cyclopentenedione & $93,69,55$ \\
\hline 7 & 7.7 & 2-Furfuryl-acetate & $140, \mathbf{9 8}, \mathbf{8 1}, 52$ \\
\hline 8 & 7.8 & Phenol & $94,66,55,39$ \\
\hline 9 & 9.3 & 5-methylfurfural & $\mathbf{1 1 0}, 95, \mathbf{8 1}, \mathbf{5 3}, 43,39$ \\
\hline 10 & 9.7 & 1H-imidazole-2-methanol & $98,81,69,53$ \\
\hline 11 & 10.2 & 2,5-dimethylfuran & $96,81,67,53$ \\
\hline 12 & 10.5 & 1,2-benzenediol & $110,92,64$ \\
\hline 13 & 10.9 & 5-acetoxymethyl-2-furaldehyde & $168,126,109,97,79,69,53,43$ \\
\hline 14 & 11.1 & Phthalic anhydride & $148, \mathbf{1 0 4}, 76,50$ \\
\hline 15 & 11.3 & Dihydro-5-propyl-furanone & 110,85 \\
\hline 16 & 14.2 & Dibutyl phthalate & $278,149,132,120,106,91,77,65,56,50,41$ \\
\hline 17 & 16.0 & Stearic acid & $284,241,185,129,111,97,85,73,57,43$ \\
\hline
\end{tabular}

A complete summary of all the results collected for the two costumes analyzed is provided in Table 5. 
Table 5. Fabrics, dyes, and metal foil constituents identified in all the samples analyzed (n.a. = not analyzed).

\begin{tabular}{|c|c|c|c|c|c|}
\hline & Sample & Color & Sampling Location & $\begin{array}{c}\text { Fabrics or Varnish/Support for } \\
\text { Metal Thread }\end{array}$ & $\begin{array}{l}\text { Identified Dyes or Metal Foil } \\
\text { Constituents }\end{array}$ \\
\hline \multirow{12}{*}{ Il Casanova } & $\mathrm{C} 1$ & Yellow & Warp & Viscose & $\begin{array}{c}\text { DY28, } \\
\text { Crystal Violet (traces) }\end{array}$ \\
\hline & $\mathrm{C} 2$ & Black & Lace applied on the neckline & Viscose & Dioxazine family \\
\hline & $\mathrm{C} 3$ & Yellow & Volant applied on the sleeve & Cotton & $\begin{array}{c}\text { DY28, } \\
\text { Crystal Violet (traces) }\end{array}$ \\
\hline & $\mathrm{C} 4$ & Yellow & Corset & Cotton & $\begin{array}{c}\text { DY28, } \\
\text { Crystal Violet (traces) }\end{array}$ \\
\hline & $\mathrm{C} 5$ & Black & Decoration of the hat & Silk & Cristal Violet \\
\hline & $\mathrm{C} 7$ & Yellow & Lace applied on the sleeve & Polyethylene & DY28 \\
\hline & $\mathrm{C} 8$ & Golden lamé & Right sleeve of the corset & $\begin{array}{l}\text { Polyester (around the metallic foil) } \\
+ \text { viscose (background) }\end{array}$ & $\mathrm{Al}$ \\
\hline & C9 & $\begin{array}{l}\text { Golden foil wrapped around a black } \\
\text { thread (C2) }\end{array}$ & Lace applied on the right side of the neckline & $\begin{array}{l}\text { Polyester (around the metallic foil) } \\
\qquad+ \text { viscose (core) }\end{array}$ & n.a. \\
\hline & $\mathrm{C} 11$ & Golden lamé & Corset decoration on the right side & Acrylic (on top of the metallic foil) & $\mathrm{Zn}, \mathrm{Cu}(\mathrm{Cl})$ \\
\hline & $\mathrm{C} 12$ & $\begin{array}{l}\text { Lace made of golden threads sewn } \\
\text { by viscose }\end{array}$ & Trimming on the left side of the neckline & $\begin{array}{l}\text { Polyester (around the metallic foil) } \\
+ \text { + viscose thread }\end{array}$ & $\mathrm{Al}$ \\
\hline & $\mathrm{C} 13$ & $\begin{array}{c}\text { Golden foil thread interwoven with a yellow } \\
\text { thread (C7) }\end{array}$ & Lace applied on the sleeve & Polyester (around the metallic foil) & n.a. \\
\hline & $\mathrm{C} 14$ & $\begin{array}{l}\text { Golden foil interwoven with black } \\
\text { thread (C5) }\end{array}$ & Decoration of the top part of the hat & Acrylic (on top of the metallic foil) & $\mathrm{Ag}, \mathrm{Cu}(\mathrm{Cl})$ \\
\hline \multirow{2}{*}{ Roma } & $\mathrm{T}$ & Yellow & Lining of the tunic & Viscose & $\begin{array}{c}\text { DY28, } \\
\mathrm{C}_{28} \mathrm{H}_{20} \mathrm{~N}_{4} \mathrm{O}_{7} \mathrm{~S}_{4}, \mathrm{C}_{28} \mathrm{H}_{18} \mathrm{~N}_{4} \mathrm{O}_{6} \mathrm{~S}_{4}\end{array}$ \\
\hline & $\mathrm{P}$ & Yellow & Inside trimming of the chasuble & Bemberg & $\begin{array}{l}\text { DY28, } \\
\text { PY1, DY3 }\end{array}$ \\
\hline
\end{tabular}




\section{Conclusions}

The present study highlights how Donati managed to exploit the potentialities of the different fabrics and new synthetic dyes to create scenic and eccentric stage costumes for Fellini's movies.

The costume of the golden lady in "Il Casanova" can be considered a metamaterial artwork composed of natural (silk), artificial (viscose), and synthetic (polyester and polyethylene) fibers, plastic inserts, and lamé made of metal foils (aluminum or alloysbrass or gold and silver) applied on synthetic supports. The different materials were used in mixture or composites for manufacturing each detail of the dress. The blackish-bluish fibers were dyed with synthetic dyes belonging to the family of triarylmethines and dioxazines. While dioxazines are known to be quite stable [44], triarylmethines are extremely photo-sensitive $[15,57]$; thus, the black dyed laces need to be protected from light during exhibitions. The metal threads were manufactured employing different metals; most of them consist of an aluminum foil placed between two layers of synthetic polymers, while two of them were varnished with an acrylic resin. The different technique employed impacted their appearance and state of conservation. The identification of the specific plastic and metal components allowed to select the appropriate cleaning strategy and consolidation material, as detailed in [58].

The analysis of the bishop costume in "Roma" evidenced how different materials were chosen in accordance with the structure and the esthetic of the costumes. The tunic is made of viscose, a cheap fabric for the underneath part of the costume, while the chasuble is composed of Bemberg, a more precious fabric, which looks like silk (hence the common name "Bemberg silk") and is, thus, ideal for a golden surface enriched with decorations and jewelries made of metallized plastic. The golden yellow fibers of the costumes from "Il Casanova" and "Roma" were both dyed with DY28, but the chasuble was most probably subjected to consecutive dyeing baths with PY1 and DY3 to provide the desired hue. The results informed the cleaning steps of the restoration procedure, highlighting that polar solvents shall not be employed for removing the stains from the chasuble [58]. This finding further points out the importance of the compatibility between artworks constituting materials, and the risks posed by possible interactions of constituting and restoration materials, especially after ageing.

The preventive conservative approach, planned to be consistent with the technical and historical features of the costumes and performed in perspective of the future collocation and exhibition of these fragile heritage objects, entailed diversified treatments for each specific constitutive element in order to reduce the crucial conservation issues responsible for the speeding up of the ageing processes. A detailed discussion on the practical and theoretical aspects of the restoration intervention is reported in a specialized publication available on [58]. A wider knowledge on these materials will enable us to distinguish and unambiguously identify them in artworks and to guide the development of innovative restoration approaches for addressing new challenging conservation issues.

From an analytical point of view, HPLC with both spectroscopic and spectrometric detectors confirmed their suitability for the detection of dyes even in microscopic samples.

With regard to the study of textile fibers, the complementary information achieved by OM, SEM morphological analysis, FTIR-ATR, and Py-GC/MS were all used to fully characterize the samples and the results allowed us to verify the limits and advantages of each technique. In particular, OM and SEM provided information on the structure of the threads, enabling us to identify silk, to distinguish vegetal fibers (cotton) from artificial fibers (viscose and Bemberg, both based on cellulose) and to highlight the presence of synthetic fibers. The characterization of the composition of synthetic fibers was only possible through FTIR or Py-GC/MS. Notably, both techniques required a comparison with reference materials or reference databases of spectra or pyrolysis profiles for a proper and unambiguous assignment. 
Summarizing, the results provided interesting hints on the potentialities offered to the costume designer by the plethora of fabrics and dyes commercialized in the 20th century and to the chemist by the wide range of techniques available for their study.

Supplementary Materials: The following are available online at https:/ /www.mdpi.com/2076-341 7/11/7/2954/s1, Table S1: Sample list with relative sampling point and analysis performed; Figure S1: 10× OM images and Secondary Electron images (SE) of samples: C1 (a and b); C2 (c and d); C3 (e and f); $\mathrm{C} 4$ ( $\mathrm{g}$ and h); Figure S2: LC-ESI-Q-ToF EIC of $\mathrm{C}_{24} \mathrm{H}_{28} \mathrm{~N}_{3}{ }^{+}$(penta-N-methyl pararosaniline) and $\mathrm{C}_{25} \mathrm{H}_{30} \mathrm{~N}_{3}{ }^{+}$(hexa-N-methyl pararosaniline) from extracts of sample $\mathrm{C} 5$. Positive acquisition mode; Figure S3: (a) OM image of sample C8; (b) Secondary Electron image (SE) of sample C8; (c) EDX spectrum of the point labeled as 1 in (b); (d) EDX spectrum of the point labeled as 2 in (b); (e) EDX spectrum of the point labeled as 3 in (b); Figure S4: (a) OM image of sample C11; (b) Secondary Electron image (SE) of sample C11; (c) EDX spectrum of the point labeled as 11 in (b); (d) EDX spectrum of the point labeled as 15 in (b); Figure S5: (a) Secondary Electron image (SE) of sample C14; (b) EDX spectrum of the point labeled as 19 in (a); (c) EDX spectrum of the point labeled as 20 in (a).

Author Contributions: S.B., F.U. and I.T. selected the samples and performed SEM analyses. C.G. and J.L.N. performed the chromatographic and ATR-FTIR analyses, F.S. and I.D. contributed in interpreting the chromatographic and mass spectrometric data. F.S., J.L.N. and I.D. wrote the manuscript. M.P.C. and F.M. managed the funding. All the authors contributed to the discussion of the results and reviewed the manuscript. All authors have read and agreed to the published version of the manuscript.

Funding: The research was supported by the University of Pisa (project "PRA_2018_26": Advanced analytical pyrolysis to study polymers in renewable energy, environment, cultural heritage-2018-2020).

Institutional Review Board Statement: Not applicable.

Informed Consent Statement: Not applicable.

Data Availability Statement: The datasets used and analyzed during the current study are available from the corresponding author on reasonable request.

Acknowledgments: The authors acknowledge the Fondazione Fellini (Rimini, Italy) for providing us with the samples and giving the permission to reproduce the photographs. The authors also acknowledge Riccardo Gennaioli, Marta Cimò, and Licia Triolo (Opificio delle Pietre Dure, Florence) for supervising the restoration project. University of Pisa is acknowledged for funding F.S.'s scholarship under the BIHO2019 program (beneficiary, Francesca Modugno).

Conflicts of Interest: The authors declare no conflict of interest.

\section{References}

1. Stone, R. Art of the Andes from Chavin to Inca (World of Art); Thames \& H: New York, NY, USA, 2012; ISBN 0500204152.

2. Grishanov, S. Structure and properties of textile materials. In Handbook of Textile and Industrial Dyeing; Clark, M., Ed.; Woodhead Publishing: Cambridge, UK, 2011; Volume 1.

3. Kauffman, G.B. Rayon: The first semi-synthetic fiber product. J. Chem. Educ. 1992, 70, 887-893. [CrossRef]

4. Clark, M. General aspects of dyeing. In Handbook of Textile and Industrial Dyeing; Clarke, M., Ed.; Woodhead Publishing: Cambridge, UK, 2011; Volume 1.

5. Restivo, A.; Degano, I.; Ribechini, E.; Pérez-Arantegui, J.; Colombini, M.P. Field-emission scanning electron microscopy and energy-dispersive X-ray analysis to understand the role of tannin-based dyes in the degradation of historical wool textiles. Microsc. Microanal. 2014, 20, 1534-1543. [CrossRef]

6. Timar-Balazsy, A.; Eastop, D. Chemical Principles of Textile Conservation; Routledge: New York, NY, USA, 1998; ISBN 9780080501048.

7. Houck, M.M. Identification of Textile Fibers; Woodhead Publishing: Cambridge, UK, 2009; ISBN 9781845692667.

8. Carrillo, F.; Colom, X.; Suñol, J.J.; Saurina, J. Structural FTIR analysis and thermal characterisation of lyocell and viscose-type fibres. Eur. Polym. J. 2004, 40, 2229-2234. [CrossRef]

9. Pereira, A.P.D.S.; Silva, M.H.P.D.; Lima Júnior, É.P.; Paula, A.D.S.; Tommasini, F.J. Processing and Characterization of PET Composites Reinforced With Geopolymer Concrete Waste. Mater. Res. 2017, 20, 411-420. [CrossRef]

10. Kakida, H.; Tashiro, K. Mechanism and kinetics of stabilization reactions of polyacrylonitrile and related copolymers III. Comparison among the various types of copolymers as viewed from isothermal DSC thermograms and FT-IR spectral changes. Polym. J. 1997, 29, 557-562. [CrossRef] 
11. Charles, J.; Ramkumaar, G.R.; Azhagiri, S.; Gunasekaran, S. FTIR and thermal studies on nylon-66 and $30 \%$ glass fibre reinforced nylon. J. Chem. 2009, 6, 23-33. [CrossRef]

12. Broda, J.; Przybyło, S.; Kobiela-Mendrek, K.; Biniaś, D.; Rom, M.; Grzybowska-Pietras, J.; Laszczak, R. Biodegradation of sheep wool geotextiles. Int. Biodeterior. Biodegrad. 2016, 115, 31-38. [CrossRef]

13. Fan, M.; Dai, D.; Huang, B. Fourier transform infrared spectroscopy for natural fibres. Fourier Transform. Anal. $2012,3,45-68$.

14. La Nasa, J.; Biale, G.; Sabatini, F.; Degano, I.; Colombini, M.P.; Modugno, F. Synthetic materials in art: A new comprehensive approach for the characterization of multi-material artworks by analytical pyrolysis. Herit. Sci. 2019, 7, 8. [CrossRef]

15. Sabatini, F.; Manariti, A.; di Girolamo, F.; Bonaduce, I.; Tozzi, L.; Rava, A.; Colombini, M.P.; Lluveras-Tenorio, A. Painting on polyurethane foam: “Composizione-Superficie Lunare” by Giulio Turcato. Microchem. J. 2020, 156, 104872. [CrossRef]

16. Yang, Y.P.; Zhang, Y.; Lang, Y.X.; Yu, M.H. Structural $\{$ ATR $\}-\{\mathrm{IR}\}$ analysis of cellulose fibers prepared from a $\{\mathrm{NaOH}\}$ complex aqueous solution. IOP Conf. Ser. Mater. Sci. Eng. 2017, 213, 12039. [CrossRef]

17. Causin, V.; Casamassima, R.; Marega, C.; Maida, P.; Schiavone, S.; Marigo, A.; Villari, A. The discrimination potential of ultraviolet-visible spectrophotometry, thin layer chromatography, and Fourier transform infrared spectroscopy for the forensic analysis of black and blue ballpoint inks. J. Forensic Sci. 2008, 53, 1468-1473. [CrossRef]

18. Degano, I.; Modugno, F.; Bonaduce, I.; Ribechini, E.; Colombini, M.P. Recent Advances in Analytical Pyrolysis to Investigate Organic Materials in Heritage Science. Angew. Chem. Int. Ed. 2018, 57, 7313-7323. [CrossRef] [PubMed]

19. Pintus, V.; Wei, S.; Schreiner, M. Accelerated UV ageing studies of acrylic, alkyd, and polyvinyl acetate paints: Influence of inorganic pigments. Microchem. J. 2016, 124, 949-961. [CrossRef]

20. La Nasa, J.; Orsini, S.; Degano, I.; Rava, A.; Modugno, F.; Colombini, M.P. A chemical study of organic materials in three murals by Keith Haring: A comparison of painting techniques. Microchem. J. 2016, 124. [CrossRef]

21. La Nasa, J.; Biale, G.; Ferriani, B.; Colombini, M.P.; Modugno, F. A pyrolysis approach for characterizing and assessing degradation of polyurethane foam in cultural heritage objects. J. Anal. Appl. Pyrolysis 2018, 134, 562-572. [CrossRef]

22. La Nasa, J.; Biale, G.; Ferriani, B.; Trevisan, R.; Colombini, M.P.; Modugno, F. Plastics in Heritage Science: Analytical Pyrolysis Techniques Applied to Objects of Design. Molecules 2020, 25, 1705. [CrossRef]

23. Xu, Y.; Lu, Z.; Tang, R. Structure and thermal properties of bamboo viscose, Tencel and conventional viscose fiber. J. Therm. Anal. Calorim. 2006, 89, 197-201. [CrossRef]

24. Muratoglu, O.K.; Argon, A.S.; Cohen, R.E.; Weinberg, M. Toughening mechanism of rubber-modified polyamides. Polymer (Guildf.) 1995, 36, 921-930. [CrossRef]

25. Buschle-Diller, G.; Zeronian, S.H.; Pan, N.; Yoon, M.Y. Enzymatic Hydrolysis of Cotton, Linen, Ramie, and Viscose Rayon Fabrics. Text. Res. J. 1994, 64, 270-279. [CrossRef]

26. El-Gaoudy, H.; Kourkoumelis, N.; Varella, E.; Kovala-Demertzi, D. The effect of thermal aging and color pigments on the Egyptian linen properties evaluated by physicochemical methods. Appl. Phys. A 2011, 105, 497-507. [CrossRef]

27. Needles, H.L.; Nowak, K.C.J. Heat-Induced Aging of Linen. In Historic Textile and Paper Materials II; American Chemical Society: Washington, DC, USA, 1989; pp. 159-167.

28. Augsten, K.; Mühlig, P.; Herrmann, C. Glycoproteins and skin-core structure in Nephila clavipes spider silk observed by light and electron microscopy. Scanning 2000, 22, 12-15. [CrossRef]

29. D'orazio, L.; Martuscelli, E.; Orsello, G.; Riva, F.; Scala, G.; Taglialatela, A. Nature, Origin and Technology of Natural Fibres of Textile Artefacts Recovered in the Ancient Cities around Vesuvius. J. Archaeol. Sci. 2000, 27, 745-754. [CrossRef]

30. El-Nagar, K.; Sanad, S.H.; Mohamed, A.S.; Ramadan, A. Mechanical Properties and Stability to Light Exposure for Dyed Egyptian Cotton Fabrics with Natural and Synthetic Dyes. Polym. Plast. Technol. Eng. 2005, 44, 1269-1279. [CrossRef]

31. Shim, W.S.; Kim, J.P.; Lee, J.J.; Koh, J.; Kim, I.S. Probing of an environmentally friendly regenerated cellulose material having bimorphic behavior. Fibers Polym. 2008, 9, 691-697. [CrossRef]

32. van Bommel, M.R.; Vanden Berghe, I.; Wallert, A.M.; Boitelle, R.; Wouters, J. High-performance liquid chromatography and non-destructive three-dimensional fluorescence analysis of early synthetic dyes. J. Chromatogr. A 2007, 1157, 260-272. [CrossRef] [PubMed]

33. Caycedo, M. Identification of Fifteen First Priority Textile Dyes from the Schweppe Collection with Raman and Surface Enhanced Raman Spectroscopy (SERS); Universiteit van Amsterdam: Amsterdam, The Netherlands, 2012.

34. Chen, V.J.; Smith, G.D.; Holden, A.; Paydar, N.; Kiefer, K. Chemical analysis of dyes on an Uzbek ceremonial coat: Objective evidence for artifact dating and the chemistry of early synthetic dyes. Dye Pigments 2016, 131, 320-332. [CrossRef]

35. Douglas, J.G.; Kavich, G.; Mori, C.; Wallace, D.; Barden, R. Materials characterization of the Ruby Slippers from the 1939 classic film, The Wizard of Oz. Herit. Sci. 2018, 6, 49. [CrossRef]

36. Liu, J.; Zhou, Y.; Zhao, P.; Peng, Z.; Wang, S. Identification of early synthetic dyes in historical Chinese textiles of the late nineteenth century by high-performance liquid chromatography coupled with diode array detection and mass spectrometry. Color. Technol. 2016, 132, 177-185. [CrossRef]

37. Sabatini, F.; Giugliano, R.; Degano, I. Photo-oxidation processes of Rhodamine B: A chromatographic and mass spectrometric approach. Microchem. J. 2018, 140, 114-122. [CrossRef]

38. Souto, C.S.C.N. Analysis of Early Synthetic Dyes with HPLC-DAD-MS; Universidade de Lisboa: Lisboa, Portugal, 2010.

39. Ursino, F. Il Costume da Vescovo Ideato da Danilo Donati per il Film Roma (1972) di Federico Fellini: Dal Comune di Rimini-Archivio Federico Fellini: Il Restauro di Un'opera Polimaterica Contemporanea; Opificio delle Pietre Dure: Florence, Italy, 2019. 
40. Gennaioli, R.; Triolo, L. Il restauro di due costumi creati da Danilo Donati per i film Roma (1972) e Il Casanova di Federico Fellini (1976). Kermes 2019, 116, 4-5.

41. Guinot, P.; Andary, C. Molecules involved in the dyeing process with flavonoids. Dye Hist. Archaeol. 2006, 25, 21-22.

42. Vasko, P.D.; Blackwell, J.; Koenig, J.L. Infrared and raman spectroscopy of carbohydrates: Part I: Identification of O-H and C-H-related vibrational modes for D-glucose, maltose, cellobiose, and dextran by deuterium-substitution methods. Carbohydr. Res. 1971, 19, 297-310. [CrossRef]

43. Wang, S.; Hu, Y.; Uzoejinwa, B.B.; Cao, B.; He, Z.; Wang, Q.; Xu, S. Pyrolysis mechanisms of typical seaweed polysaccharides. J. Anal. Appl. Pyrolysis 2017, 124, 373-383. [CrossRef]

44. Herbst, W.; Hunger, K.; Wilker, G.; Ohleier, H.; Winter, R. Industrial Organic Pigments, 3rd ed.; Herbst, W., Hunger, K., Wilker, G., Ohleier, H., Eds.; Wiley-VCH Verlag GmbH \& Co. KGaA: Weinheim, Germany, 2004; ISBN 9783527602421.

45. Teramoto, H.; Miyazawa, M. Molecular Orientation Behavior of Silk Sericin Film as Revealed by ATR Infrared Spectroscopy. Biomacromolecules 2005, 6, 2049-2057. [CrossRef]

46. Orsini, S.; Parlanti, F.; Bonaduce, I. Analytical pyrolysis of proteins in samples from artistic and archaeological objects. J. Anal. Appl. Pyrolysis 2017, 124, 643-657. [CrossRef]

47. Degano, I.; Sabatini, F.; Braccini, C.; Colombini, M.P. Triarylmethine dyes: Characterization of isomers using integrated mass spectrometry. Dye Pigments 2019, 160, 587-596. [CrossRef]

48. Gessner, T.; Mayer, U. Triarylmethane and Diarylmethane Dyes. In Ullmann's Encyclopedia of Industrial Chemistry; Wiley-VCH Verlag GmbH \& Co. KGaA: Weinheim, Germany, 2000.

49. Tsuge, S.; Ohtani, H.; Watanabe, C. Pyrolysis-GC/MS Data Book of Synthetic Polymers; Elsevier: Amsterdam, The Netherlands, 2011; ISBN 9780444538925.

50. Duran, A.; Perez-Maqueda, R.; Perez-Rodriguez, J.L. Degradation processes of historic metal threads used in some Spanish and Portuguese ornamentation pieces. J. Cult. Herit. 2019, 36, 135-142. [CrossRef]

51. Láró, M.; Gál, T.; Tóth, A. The Characterization and Deterioration of Modern Metallic Threads. Stud. Conserv. 2000, 45, 95-105. [CrossRef]

52. Asensio, R.C.; Moya, M.S.A.; de la Roja, J.M.; Gómez, M. Analytical characterization of polymers used in conservation and restoration by ATR-FTIR spectroscopy. Anal. Bioanal. Chem. 2009, 395, 2081-2096. [CrossRef] [PubMed]

53. Vijayakumar, S.; Rajakumar, P.R. Infrared spectral analysis of waste pet samples. Int. Lett. Chem. Phys. Astron. 2012, 4, 58-65. [CrossRef]

54. Dunn, T.B.T.-F.P. (Ed.) 22-Oriented Plastic Films; William Andrew Publishing: Oxford, UK, 2015; pp. 177-185. ISBN 978-0-323-26436-5.

55. Tebelius, L.K.; Stetz, E.M.; Urban, M.W. Surface and interfacial fourier transform infrared spectroscopic studies of latexes. XIV. Surface phase separation in polystyrene/poly-n-butyl acrylate latex films. J. Appl. Polym. Sci. 1996, 62, 1887-1892. [CrossRef]

56. Disperse Yellow 3. In Iarc Monographs of the Evaluation of Carcinogenic Risks to Humans; IARC: Lyon, France, 1990; Volume 48, pp. 149-159.

57. Confortin, D.; Neevel, H.; Van Bommel, M.; Reissland, B. Crystal Violert: Study of the Degradation of an Early Synthetic Dye, Crystal Violet. J. Phys. Conf. Ser. 2010, 231, 197-201.

58. Bonadio, S.; Cimò, M.; Triolo, L.; Ursino, F. Il restauro dell'effimero. Due costumi di Danilo Donati per i film Roma (1972) e Il Casanova di Federico Fellini (1976). Kermes 2020, 31, 216-227. 